\title{
ONE-SIDED STAR PARTIAL ORDER PRESERVERS ON $B(H)$
}

\author{
Gregor Dolinar, Bojan KuzMa, Janko Marovt and EdWARd PoOn
}

Abstract. Let $B(H)$ be the algebra of all bounded linear operators on a complex Hilbert space $H$. We classify (possibly non-additive) maps on $B(H)$, with $H$ infinite dimensional, which preserve either the left-star or the right-star partial order in both directions. We also introduce natural, weaker versions of these partial orders and classify their preservers.

Mathematics subject classification (2020): Primary 47B49; Secondary 15A86, 06A06. Keywords and phrases: Left-star order, right-star order, preserver, Hilbert space.

\section{REFERENCES}

[1] J. K. Baks alary, S. K. Mitra, Left-star and right-star partial orderings, Linear Algebra Appl. 149 (1991), 73-89.

[2] B. BlackADAR, Operator algebras: Theory of $C^{*}$-algebras and von Neumann algebras, Springer, Berlin, 2006.

[3] G. Dolinar, A. Guterman, J. Marovt, Automorphisms of $K(H)$ with respect to the star partial order, Oper. Matrices 7 (2013), No. 1, 225-239.

[4] G. Dolinar, A. Guterman, J. Marovt, Monotone transformations on B $(H)$ with respect to the left-star and the right-star partial order, Math. Inequal. Appl. 17 (2014), No. 2, 573-589.

[5] G. Dolinar, S. Halicioglu, A. Harmanci, B. Kuzma, J. Marovt, B. Ungor, Preservers of the left-star and rigt-star partial orders, Linear Algebra Appl. 587 (2020), 70-91.

[6] M. P. DraZIN, Natural structures on semigroups with involution, Bull. Amer. Math. Soc. 84 (1978), 139-141.

[7] P. A. Fillmore, W. E. LongstafF, On isomorphisms of lattices of closed subspaces, Can. J. Math. 5 (1984), 820-829.

[8] A. E. Guterman, Monotone additive transformations on matrices, Mat. Zametki 81 (2007), 681692.

[9] R. Hagen, S. Roch, B. Sibermann, $C^{*}$ algebras and numerical analysis, CRC Press, Boca Raton, 2001.

[10] P. LEGIŠA, Automorphisms of $M_{n}$, partially ordered by the star order, Linear Multilinear Algebra 54, No. 3, 157-188, 2006.

[11] L. Molnár, Local automorphisms of operator algebras on Banach spaces, Proc. Amer. Math. Soc. 131 (2003), No. 6, 1867-1874.

[12] M. Z. NASHED (ed.), Generalized inverses and applications, Academic Press, New York-London, 1976. 